\title{
Article \\ Physical Activity, Sedentary Behavior, Sleep and Self-Regulation in Spanish Preschoolers during the COVID-19 Lockdown
}

\author{
Alicia M. Alonso-Martínez ${ }^{1}$, Robinson Ramírez-Vélez ${ }^{1,2} \mathbb{D}$, Yesenia García-Alonso ${ }^{2} \mathbb{D}$, Mikel Izquierdo $^{1,2,+}$ (D) \\ and Antonio García-Hermoso $2,3, *,+$
}

check for updates

Citation: Alonso-Martínez, A.M.; Ramírez-Vélez, R.; García-Alonso, Y.; Izquierdo, M.; García-Hermoso, A. Physical Activity, Sedentary Behavior Sleep and Self-Regulation in Spanish Preschoolers during the COVID-19 Lockdown. Int. J. Environ. Res. Public Health 2021, 18, 693. https:// doi.org/10.3390/ijerph18020693

Received: 15 December 2020 Accepted: 13 January 2021 Published: 15 January 2021

Publisher's Note: MDPI stays neutral with regard to jurisdictional clai$\mathrm{ms}$ in published maps and institutional affiliations.

Copyright: (C) 2021 by the authors. Licensee MDPI, Basel, Switzerland. This article is an open access article distributed under the terms and conditions of the Creative Commons Attribution (CC BY) license (https:// creativecommons.org/licenses/by/ $4.0 /)$.
1 Department of Health Sciences, Public University of Navarra, CIBER of Frailty and Healthy Aging (CIBERFES), Instituto de Salud Carlos III, 31006 Pamplona, Spain; aliciamaria.alonso@unavarra.es (A.M.A.-M.); robin640@hotmail.com (R.R.-V.); mikel.izquierdo@gmail.com (M.I.)

2 Navarrabiomed, Complejo Hospitalario de Navarra (CHN), Universidad Pública de Navarra (UPNA), IdiSNA, 31008 Pamplona, Spain; yesenia.garcia.ihs@gmail.com

3 Laboratorio de Ciencias de la Actividad Física, el Deporte y la Salud, Facultad de Ciencias Médicas, Universidad de Santiago de Chile, USACH, 71783-5 Santiago, Chile

* Correspondence: antonio.garciah@unavarra.es

+ Authors contributed equally.

\begin{abstract}
Background: A better understanding of the effects of the lockdown on lifestyle behaviors may help to guide the public health response to COVID-19 at a national level and to update the global strategy to respond COVID-19 pandemic. The aim of the study was to examine the effects of the COVID-19 lockdown on device-measured physical activity (PA), sedentary time, sleep and self-regulation; and to determine whether PA and sleep are related to self-regulation problems during the lockdown. Methods: PA, sedentary time and sleep were assessed using accelerometry in the week in which the Spanish national state of alarm was declared $(n=21)$. Parents reported preschooler's self-regulation difficulties (internalizing and externalizing) before $(n=268)$ and during the lockdown ( $n=157$ ) by a validated questionnaire. Results: Preschoolers showed a decrease in total PA (mean difference $[M D]=-43.3$ min per day, $95 \% \mathrm{CI}-68.1$ to -18.5$)$, sleep efficiency $(\mathrm{MD}=-2.09 \%, 95 \%$ CI -4.12 to -0.05 ), an increase in sedentary time (MD $=50.2 \mathrm{~min}$ per day, $95 \%$ CI 17.1 to 83.3 ) internalizing ( $\mathrm{MD}=0.17,95 \% \mathrm{CI} 0.06$ to 0.28 ) and externalizing ( $\mathrm{MD}=0.33,95 \% \mathrm{CI} 0.23$ to 0.44 ) problems. Preschoolers who met the World Health Organization recommendations for PA had lower internalizing scores than non-active peers ( $\mathrm{MD}=-1.28,95 \% \mathrm{CI}-2.53$ to -0.03$)$. Conclusions: Our findings highlight the importance of meeting PA recommendations to reduce psychosocial difficulties during a lockdown situation.
\end{abstract}

Keywords: coronavirus; quarantine; healthy lifestyle; mental health

\section{Introduction}

The coronavirus 2 (SARS-CoV-2, COVID-19) is a severe acute respiratory syndrome that first emerged in late 2019. Countries have faced challenges with how to handle the crisis in different ways. Specifically, in March 2020, the Government of Spain declared a national state of alarm to curb the spread of the severe acute respiratory syndrome coronavirus 2 and established a mandatory home "lockdown" from 14 March to 26 April. Accordingly, the coronavirus disease 2019 (COVID-19) pandemic disrupted life for all, with the closure of non-essential businesses and schools. For schoolchildren, this limited the opportunities for movement (i.e., children no longer had access to school-based physical activities such as physical education, recess, and walking to/from school) and social life, disrupting daily schedules and routines. Many children and adolescents were temporarily 
deprived of institutional, educational environments, social contact with peers and, possibly, adequate cognitive, affective and physical stimuli for their age.

Recent studies published about healthy lifestyles during confinement have shown adverse collateral effects of the COVID-19 lockdown on physical health [1] in children and adolescents. It has been shown that U.S. children performed less physical activity and engaged in more sedentary behavior during the early COVID-19 period as compared to before the pandemic [2]. Another study in Spanish children and adolescents ( 3 to 16 years old) also reported a reduction in physical activity levels and increased both screen exposure and sleep time [3]. Specifically, these authors suggested that preschoolers (i.e., 3 to 4 years old) reduced their total physical activity ( $92 \mathrm{~min}$ per day) and increased screen time exposure by $2.2 \mathrm{~h}$ per day. In contrast, another study showed that during the pandemic Swedish preschooler's physical activity, time spent outside on weekdays and weekend days, and screen time significantly increased [4]. However, it should be noted that in Sweden, preschools, playgrounds, and parks remained open, and children's organized sports and activities continued.

Several studies have reported serious changes in the mental health of children and adolescents during the COVID-19 quarantine [5]. For example, research carried out in China informed an increase in depressive, anxiety and stress symptoms during the COVID-19 lockdown [6,7]. A recent narrative review analyzed the impact of COVID-19 and lockdown on the mental health of children and adolescents and suggested that young children show more clinginess, poor appetite, inattentiveness, and significant separation problems [8]. In another study published in Spain, when the families described the observed changes in the psychological well-being of children aged three years old, they mentioned greater difficulties in self-regulation [9]. Self-regulation refers to the ability to control one's thoughts, behaviors, emotional reactions, and social interactions, even when impulses and urges run contrary to proximal or distal goals [10] and is recognized as an indicator of positive child development [11].

Regarding sleep patterns, studies have shown inconclusive results in the youth population. Overall, the pandemic seems to significantly disturb normal sleep patterns and nightmares for children [8]. The above-mentioned study among Spanish youth reported different results according to age group, showing an increase of sleep time of $0.6 \mathrm{~h}$ per day among adolescents (13 to 16 years old) but a reduction of $0.4 \mathrm{~h}$ per day in preschoolers [3]. Pietrobelli et al. also showed an increase of $0.65 \mathrm{~h}$ per day of sleep time among obese Italian children [1].

A better understanding of the effects of the lockdown on physical activity, sleep and mental health may help to develop suitable strategies as part of the COVID-19 pandemic responses. In this regard, the compulsory movement restriction meant the prohibition of the movement of children outside their home for many weeks in a row, with no certainty about potentially damaging consequences on their health and well-being. Therefore, the purpose of this study was two-fold: to examine the effects of the COVID-19 lockdown on physical activity, sedentary time, sleep and self-regulation in Spanish preschoolers; and to determine whether device-measured PA and sleep are related to self-regulation difficulties during lockdown.

\section{Materials and Methods}

\subsection{Design and Population Study}

The present study was conducted in a cohort of preschoolers aged 4 to 6 years old from three schools in Pamplona (Spain). Data from baseline assessments (from September to December 2019) and from the second evaluation (from March to April 2020) were included in the study. The Ethics Committee of the Public University of Navarra approved the study protocol (PI-020/19). Before the enrollment in the study, all parents or legal guardians were informed about the purpose of the project and signed informed consent. 


\subsection{Procedures}

\subsubsection{Physical Activity, Sedentary Behavior and Sleep}

Objectively measured physical activity, sedentary time, and sleep were collected using a wrist-worn GENEActiv tri-axial accelerometer attached to the preschooler's nondominant wrist over six consecutive days [12]. Raw data were sampled at $87.5 \mathrm{~Hz}$ and then reintegrated into 1-s epochs using the GGIR package in $\mathrm{R}$ (version 1.10-7) (R Foundation for Statistical Computing, Vienna, Austria), which auto-calibrated the recorded accelerometer signals [13]. Total physical activity was defined as total recorded counts/wear time. The accelerometer counts for light, moderate and vigorous physical activity were coded using previously validated specific cut-points for preschool-aged children [14]. To meet the study inclusion criteria, preschoolers must have worn the monitor for $\geq 600$ min during awake time and an average sleep time $\geq 200 \mathrm{~min}$, each of the six days recorded. We used the World Health Organization (WHO) recommendations of physical activity ( $\geq 180 \mathrm{~min}$ per day of total physical activity including $\geq 60 \mathrm{~min}$ per day of moderate to vigorous physical activity) and sleep (10 to $13 \mathrm{~h}$ per day) [15] to determine its compliance.

In this study, the van Hees et al. [16] sleep algorithm was used to detect sleep and wake between self-reported bedtime and get uptime. This method is based on the variability of the orientation of the accelerometer and classifies each five seconds epoch as either sleep or wake. For the purpose of this study, we used sleep duration (i.e., the difference between sleep onset and offset) and efficiency (i.e., the percent of minutes scored as sleep between onset and offset). This device has been shown to correlate well with polysomnography [16].

For the present purpose, we have used data from 21 children ( $57.1 \%$ boys) who wore the accelerometers in the week in which the state of alarm was declared. For analyses, we used the three days prior to lockdown compared to the three days during the lockdown.

\subsubsection{Self-Regulation}

We used the child self-regulation and behavior questionnaire (CSBQ), which evaluates subscales of cognitive self-regulation, behavioral self-regulation, and emotional self-regulation, as well as sociability, prosocial behavior, externalizing problems and internalizing problems. Each item requests the respondent to evaluate the general frequency of target behaviors on a scale from 1 (not true) to 5 (certainly true). All subscales contain at least 5 items and have been shown to be reliable in preschoolers [10]. Following recommendations for low-risk and general populations, we employed the two subscale model of the questionnaire [17]: externalizing and internalizing problems. Externalizing behaviors include problems such as attention difficulties, self-regulation deficits, antisocial behaviors, aggression, delinquency, and other "undercontrolled" behaviors. Internalizing behaviors include problems such as social withdrawal, loneliness, sense of inferiority, depression, shyness, anxiety, somatic complaints, and other "overcontrolled" behaviors [18].

For the present study, parents reported preschoolers' psychosocial difficulties before ( $n=268$, first assessment) and during ( $n=157$, from March to April 2020) the COVID-19 lockdown using an online questionnaire that included the CSBQ [10]. This scale presents a high level of reliability (all Cronbach's $\alpha>0.80$ ).

\subsubsection{Confounders}

Potential confounders identified in previous literature were included in the analyses: Maternal education level was recorded by asking mothers about the highest level of education, dichotomized as university education and below. Maternal education is a key predictor of other resources within the family that strongly predict children's wellbeing [19]. Socioeconomic status was measured according to the level of average income per family unit. Socioeconomic factors seem to be lifestyle determinants during the COVID19 lockdown in children and adolescents [20]. Finally, the students were weighed and measured in light clothing and barefoot. These measurements were used to calculate the BMI $\left(\mathrm{kg} / \mathrm{m}^{2}\right)$, which was computed as the weight $(\mathrm{kg})$ divided by the square of the height 
$\left(\mathrm{m}^{2}\right)$. BMI seems to be an important factor related to physical activity levels during the COVID-19 lockdown [1].

\subsection{Statistical Analysis}

The data are presented as means (standard deviations, $\mathrm{SD}$ ) or absolute and relative prevalence $(n[\%])$. A test of normality of distribution and equality of variance between groups using the Shapiro-Wilk test and Levene's test were used. All assumptions were met, and an analysis of covariance was employed to evaluate differences before and during the COVID-19 lockdown in physical activity (total and moderate to vigorous physical activity), sedentary time, sleep (duration and efficiency), and self-regulation parameters (externalizing and internalizing scores). Also, we determined differences in self-regulation parameters according to compliance with the $\mathrm{WHO}$ recommendations of physical activity and sleep [15]. These analyses were adjusted for age, sex, monthly family income, maternal education, body mass index, and baseline values. Since physical activity and sedentary behavior are codependent, both physical activity parameters (i.e., total and moderate-tovigorous physical activity) were additionally adjusted by sedentary time, as well as for sedentary time by total physical activity. Results were analyzed with SPSS (version 26.0) (SPSS Inc., Chicago IL, USA), and a $p<0.05$ was considered statistically significant.

\section{Results}

Table 1 summarizes the characteristics of the sample of preschoolers. There were differences in baseline characteristics between preschoolers that participated or not in the lockdown evaluation only in the number of boys $(p=0.002)$ and in maternal education $(p<0.001)$.

Table 1. Characteristics of the whole sample of preschoolers participating in the study before the lockdown, and differences in baseline characteristics between preschoolers that participated or not in the lockdown evaluation.

\begin{tabular}{|c|c|c|c|c|}
\hline & $\begin{array}{l}\text { Whole Sample } \\
\qquad(n=268)\end{array}$ & $\begin{array}{l}\text { Preschoolers Not } \\
\text { Participating in the } \\
\text { Lockdown Evaluation } \\
\quad(n=123)\end{array}$ & $\begin{array}{c}\text { Preschoolers } \\
\text { Participating in the } \\
\text { Lockdown Evaluation } \\
\quad(n=145)\end{array}$ & $p$ \\
\hline \multicolumn{5}{|l|}{ Sociodemographic characteristics } \\
\hline Age, years & $4.28(0.80)$ & $4.27(0.84)$ & $4.29(0.76)$ & 0.890 \\
\hline Boys, $n(\%)$ & $143(53.4)$ & $70(56.9)$ & $73(46.5)$ & 0.002 \\
\hline Public school, $n(\%)$ & $28(10.4)$ & $18(14.6)$ & $10(6.9)$ & 0.067 \\
\hline Monthly family income ${ }^{a}, n(\%)$ & $102(38.2)$ & $45(36.6)$ & $58(40.2)$ & 0.229 \\
\hline Maternal education $\mathrm{b}, n(\%)$ & $146(43.6)$ & $56(25.1)$ & $90(62.1)$ & $<0.001$ \\
\hline \multicolumn{5}{|l|}{ Anthropometric variables } \\
\hline Body weight, kg & $18.90(3.33)$ & $19.14(3.65)$ & $18.64(2.97)$ & 0.255 \\
\hline Height, $\mathrm{cm}$ & $107.74(7.17)$ & $107.88(7.74)$ & $107.61(6.57)$ & 0.771 \\
\hline Body mass index, $\mathrm{kg} / \mathrm{m}^{2}$ & $16.18(1.50)$ & $16.33(1.58)$ & $16.03(1.40)$ & 0.119 \\
\hline \multicolumn{5}{|l|}{ Device-measured physical activity } \\
\hline $\begin{array}{l}\text { Total physical activity, minutes per } \\
\text { day }\end{array}$ & $361.3(67.1)$ & $363.9(69.0)$ & $346.9(54.6)$ & 0.351 \\
\hline MVPA, minutes per day & $89.0(31.9)$ & $88.5(32.8)$ & $91.6(26.7)$ & 0.684 \\
\hline Sedentary time, minutes per day & $620.6(80.3)$ & $622.4(82.0)$ & $609.6(69.4)$ & 0.513 \\
\hline Total wear time, hours & $152.3(25.6)$ & $153.3(26.7)$ & $146.1(16.6)$ & 0.233 \\
\hline Meeting recommendations ${ }^{\mathrm{c}}, n(\%)$ & $113(79.0)$ & $95(77.9)$ & $18(85.7)$ & 0.131 \\
\hline \multicolumn{5}{|l|}{ Device-measured sleep } \\
\hline Sleep duration, hours per day & $9.43(0.69)$ & $9.42(0.66)$ & $9.51(0.74)$ & 0.276 \\
\hline Sleep efficiency, \% & $84(0.04)$ & $84(0.04)$ & $84.3(4.55)$ & 0.691 \\
\hline Meeting recommendations $\mathrm{d}, n(\%)$ & $29(20.3)$ & $23(18.9)$ & $6(28.6)$ & 0.051 \\
\hline \multicolumn{5}{|l|}{ Self-regulation } \\
\hline Internalizing problems (0-5) & $1.99(0.64)$ & $2.17(0.69)$ & $1.82(0.59)$ & 0.112 \\
\hline Externalizing problems (0-5) & $2.55(0.46)$ & $2.60(0.45)$ & $2.51(0.48)$ & 0.667 \\
\hline
\end{tabular}

Notes: ${ }^{a}$ More or equal than 3000 euros $(€) ;{ }^{b}$ mother with university studies; ${ }^{c} \geq 180 \mathrm{~min} /$ day of total physical activity including $\geq 60$ $\mathrm{min} /$ day of moderate-to-vigorous physical activity; ${ }^{\mathrm{d}} 10-13 \mathrm{~h} /$ day. MVPA, moderate-to-vigorous physical activity. 
During the lockdown, preschoolers showed a decrease in total physical activity (mean difference $(\mathrm{MD})=-43.3$ min per day, $95 \%$ confidence interval $(\mathrm{CI})-68.1$ to -18.5 ) and sleep efficiency $(\mathrm{MD}=-2.09 \%, 95 \% \mathrm{CI}-4.14$ to -0.04$)$, and an increase in sedentary time $(\mathrm{MD}=50.2 \mathrm{~min}$ per day, $95 \%$ CI 17.1 to 83.3 ) and internalizing (MD $=0.17,95 \% \mathrm{CI} 0.06$ to 0.28 ) and externalizing ( $\mathrm{MD}=0.33,95 \% \mathrm{CI} 0.23$ to 0.44 ) problems (Table 2).

Table 2. Changes in physical activity, sedentary time, sleep and psychosocial parameters before and during the coronavirus disease 2019 (COVID-19) lockdown in those preschoolers participating in the two evaluations.

\begin{tabular}{|c|c|c|c|c|}
\hline & $\begin{array}{l}\text { Before the } \\
\text { Lockdown }\end{array}$ & $\begin{array}{l}\text { During the } \\
\text { Lockdown }\end{array}$ & $\begin{array}{l}\text { Mean Differences } \\
(95 \% \mathrm{CI})\end{array}$ & $p^{*}$ \\
\hline \multicolumn{5}{|l|}{ Device-measured physical activity $(n=21)$} \\
\hline $\begin{array}{l}\text { Total physical activity, minutes per } \\
\text { day }\end{array}$ & $346.9(54.6)$ & $303.6(76.5)$ & $\begin{array}{c}-43.3(-68.1 \text { to } \\
-18.5)\end{array}$ & 0.002 \\
\hline MVPA, minutes per day & $91.6(26.7)$ & $74.6(26.0)$ & $\begin{array}{c}-17.0(-21.7 \text { to } \\
-12.4)\end{array}$ & $<0.001$ \\
\hline Sedentary time, minutes per day & $609.6(69.4)$ & $659.8(116.6)$ & $50.2(17.1$ to 83.3$)$ & 0.006 \\
\hline \multicolumn{5}{|l|}{ Device-measured sleep $(n=21)$} \\
\hline Sleep duration, hours per day & $9.51(0.74)$ & $9.54(1.30)$ & $0.022(-0.41$ to 0.45$)$ & 0.914 \\
\hline Sleep efficiency, \% & $84.3(4.55)$ & $82.2(4.92)$ & $\begin{array}{c}-2.09(-4.14 \text { to } \\
-0.04)\end{array}$ & 0.047 \\
\hline \multicolumn{5}{|l|}{ Self-regulation $(n=157)$} \\
\hline Internalizing problems (0-5) & $1.82(0.59)$ & $1.99(0.68)$ & $0.17(0.06$ to 0.28$)$ & 0.003 \\
\hline Externalizing problems $(0-5)$ & $2.51(0.48)$ & $2.85(0.63)$ & $0.33(0.23$ to 0.44$)$ & $<0.001$ \\
\hline
\end{tabular}

Notes: CI, confidence interval; MVPA, moderate to vigorous physical activity. ${ }^{*}$ Differences in changes were examined by adjusting for age, sex, monthly family income, maternal education, body mass index, and baseline values. Total and moderate-to-vigorous physical activity were additionally adjusted by sedentary time and sedentary time by total physical activity, respectively.

Preschoolers who met the recommendations for physical activity had lower internalizing scores than non-active peers ( $\mathrm{MD}=-1.28,95 \% \mathrm{CI}-2.53$ to $-0.03, p=0.046)$, but not for externalizing scores (MD $=-0.61,95 \% \mathrm{CI}-1.96$ to $0.74, p=0.300)$. Regarding sleep, there were no differences between preschoolers who met or not sleep recommendations (internalizing, $\mathrm{MD}=-0.03,95 \% \mathrm{CI}-1.06$ to $0.99, p=0.940$; externalizing, $\mathrm{MD}=0.06,95 \%$ CI -0.69 to $0.82, p=0.839$ ).

\section{Discussion}

The current study explored the effects of the COVID-19 lockdown on physical activity, sedentary behavior and sleep and its relationship with self-regulation difficulties in Spanish preschoolers. Our findings provide evidence of the negative effects of the COVID-19 lockdown on physical activity level, sedentary behavior, sleep quality and self-regulation in Spanish preschoolers. As far as we know, this is the first study that objectively examines the effect of COVID-19 home confinement on these parameters among preschoolers.

Regarding physical activity and sedentary behavior, our study reflects that preschoolers reduced their total physical activity $(\mathrm{MD}=-43.3 \mathrm{~min}$ per day) and increased sedentary time (MD = $50.2 \mathrm{~min}$ per day) during the lockdown. Previously published studies are in line with our findings, which found that children had different patterns of activity than what was seen before COVID-19. For example, changes in physical activity and sedentary behavior were reported by parents and legal guardians of children living in the U.S. using an online survey [2]. Among Spanish youth, the lockdown substantially reduced physical activity levels ( $\mathrm{MD}=-102.5 \mathrm{~min}$ per week) and increased daily hours of screen time ( $\mathrm{MD}=2.9 \mathrm{~h}$ per day); suggesting that restrictive mobility measures with the closure of schools and high schools had played an important role in these lifestyle behaviors worsening [3]. With higher time spent at home, it can be expected that screen time could reach higher levels than before the COVID-19 lockdown. Therefore, our findings support objectively the hypothesis that unfavorable changes in activity behaviors occurred in preschoolers during a non-school lockdown period. Contrariwise, another study in 
100 Swedish preschoolers reported an increased in physical activity and time spent outside on weekdays and weekend days during the lockdown, but also increased screen time used ( $\mathrm{MD}=30 \mathrm{~min}$ per day) [4]. These results could be due to the that preschools, playgrounds, and parks in Sweden remained open and children's organized sports and activities continued and; therefore, preschools changed their routines to have children outside as much as possible. This study also revealed that active play indoors does not seem to replace active play outdoors, resulting in a net decline in reported play-based activity [4].

Because children and adolescents were experiencing changes regarding their usual daily habits, it also appears reasonable to find different sleep patterns. However, the results of this issue are inconclusive. For example, a recent narrative meta-analysis suggested that the pandemic seems to significantly disturb normal sleep patterns and nightmares for children [8]. The study mentioned above among Spanish youth reported different results according to age group, showing an increase of sleep time of $0.6 \mathrm{~h}$ per day among adolescents ( 13 to 16 years old) but a reduction of $0.4 \mathrm{~h}$ per day in preschoolers ( 3 to 4 years old) [3]. Pietrobelli et al. also showed an increase of $0.65 \mathrm{~h}$ per day of sleep time among obese Italian children [1]. Consistent with the above-mentioned review, the present research found that preschoolers slightly reduced their sleep efficiency (i.e., the percent of minutes scored as sleep between onset and offset), but not sleep duration. The changes in daily routines, including the lack of social activities with other children, have probably contributed to the sleep quality impairments [21]. Because sleep is a critical part of health for youths, children and families should adjust their sleep schedules to be well-rested and to have appropriate levels of energy to start their day [22].

Self-regulation is defined as psychological conduct that comprises a series of important competencies, such as the ability to control inner states or responses towards thoughts, attention, emotions or even performance [11]. The present study showed that during the lockdown, preschoolers had an increase in internalizing and externalizing problems. Behavioral and emotional problems at this age may potentially set a child on a course of maladaptation [18], and more specifically on a pathway to internalizing (i.e., antisocial behaviors) or externalizing problems (i.e., anxious or depressed behaviors). In accordance with the present research, recent studies have suggested that the pandemic situation entailed a substantial impact on mental health [23]. This finding was also reported by Giménez-Dasí et al. [9]. In this study, families reported overall greater difficulties in emotional regulation (i.e., he/she is more irritable, has more mood swings) in their children aged three years old during the six weeks of strict confinement experienced in Madrid, Spain.

Our study also shows that preschoolers who met the recommendations for physical activity had lower internalizing scores than non-active peers. Therefore, we also highlight the importance of meeting physical activity recommendations in the early years, as it seems to influence aspects related to broad areas of mental health [24]. This result may be explained by the fact that increased physical activity was associated with higher mental health among children and adolescents [24]. In this aspect, it also has recently been shown that children who meet the physical activity guidelines have higher life satisfaction, positive affect [25] and self-regulation [26] compared to inactive peers. The current results are supported by another study [27] showing that engaging in physical activity, particularly vigorous physical activity, had a beneficial association with preschoolers internalizing problems one year later. It is plausible that the activity of higher intensities may be associated with neurochemical pathways that underpin psychosocial factors that may lead to fewer emotional problems during childhood [28].

As far as we are aware, this is the first study to examine physical activity and sleep patterns of preschoolers using objective-measures with accelerometers during the COVID19 lockdown. Despite efforts of objectively examining physical activity and sleep via actigraphy, there are a number of methodological issues that also need to be considered. A first limitation is that it is possible that changes in behavior outcomes occurred in the initial week of the lockdown, as there were serious alterations in daily life and families 
struggled to adapt to their new reality. However, because the lockdown continued for several weeks, it is possible that preschoolers returned to normalcy, including their routine of sleep and physical activity. Second, the small sample size with accelerometry data and a short time of track are other important limitations. Third, subjects at such age are dependent on parents' decisions regarding their lifestyle. Finally, the geographic/urban environment could influence physical activity and sleep patterns during the early years [20].

\section{Conclusions}

In conclusion, recognizing these lifestyle and psychological well-being changes are critical because they may have a lasting impact on preschoolers' physical and mental health and may help guide future interventions, perhaps by physical activity promotion. Therefore, adopting healthy movement behaviors may help to mitigate the negative effects on preschool children of this pandemic and its lockdown.

Author Contributions: Conceptualization, A.M.A.-M. and A.G.-H.; methodology, A.M.A.-M., R.R.-V., M.I. and A.G.-H.; software, A.G.-H.; validation, A.M.A.-M. and A.G.-H.; formal analysis, A.G.-H.; investigation, A.M.A.-M., Y.G.-A., A.G.-H.; resources, A.M.A.-M. and A.G.-H.; data curation, A.G.-H.; writing-original draft preparation, A.M.A.-M., M.I. and A.G.-H.; writing—review and editing, A.M.A.-M., R.R.-V., M.I. and A.G.-H.; project administration, A.M.A.-M. and Y.G.-A.; funding acquisition, A.M.A.-M. All authors have read and agreed to the published version of the manuscript.

Funding: This study was funded by grant CENEDUCA1/2019 from the Department of Education of the Government of Navarra (Spain).

Institutional Review Board Statement: The study was conducted according to the guidelines of the Declaration of Helsinki, and approved by the Institutional Review Board (or Ethics Committee) of Public University of Navarra (PI-020/19; 16-09-2018).

Informed Consent Statement: Informed consent was obtained from all subjects involved in the study.

Acknowledgments: A.G.-H. is a Miguel Servet Fellow (Instituto de Salud Carlos III-FSE-CP18/0150). R.R.-V. is funded in part by a Postdoctoral Fellowship Resolution ID 420/2019 of the Universidad Pública de Navarra.

Conflicts of Interest: The authors declare no conflict of interest.

\section{References}

1. Pietrobelli, A.; Pecoraro, L.; Ferruzzi, A.; Heo, M.; Faith, M.S.; Zoller, T.; Antoniazzi, F.; Piacentini, G.; Fearnbach, S.N.; Heymsfield, S.B. Effects of COVID-19 Lockdown on Lifestyle Behaviors in Children with Obesity Living in Verona, Italy: A Longitudinal Study. Obesity 2020, 28, 1382-1385. [CrossRef] [PubMed]

2. Dunton, G.F.; Do, B.; Wang, S.D. Early effects of the COVID-19 pandemic on physical activity and sedentary behavior in children living in the U.S. BMC Public Health 2020, 20, 1351. [CrossRef] [PubMed]

3. López-Bueno, R.; López-Sánchez, G.F.; Casajus, J.A.; Calatayud, J.; Gil-Salmerón, A.; Grabovac, I.; Tully, M.A.; Smith, L. HealthRelated Behaviors Among School-Aged Children and Adolescents During the Spanish Covid-19 Confinement. Front. Pediatr. 2020, 8, 573. [CrossRef] [PubMed]

4. Nyström, C.D.; Alexandrou, C.; Henström, M.; Nilsson, E.; Okely, A.D.; El Masri, S.W.; Löf, M. International Study of Movement Behaviors in the Early Years (SUNRISE): Results from SUNRISE Sweden's Pilot and COVID-19 Study. Int. J. Environ. Res. Public Health 2020, 17, 8491. [CrossRef]

5. Brooks, S.K.; Webster, R.K.; Smith, L.E.; Woodland, L.; Wessely, S.; Greenberg, N.; Rubin, G.J. The psychological impact of quarantine and how to reduce it: Rapid review of the evidence. Lancet 2020, 395, 912-920. [CrossRef]

6. Tang, S.; Xiang, M.; Cheung, T.; Xiang, Y.-T. Mental health and its correlates among children and adolescents during COVID-19 school closure: The importance of parent-child discussion. J. Affect. Disord. 2021, 279, 353-360. [CrossRef]

7. Xie, X.; Xue, Q.; Zhou, Y.; Zhu, K.; Liu, Q.; Zhang, J.; Song, R. Mental Health Status Among Children in Home Confinement During the Coronavirus Disease 2019 Outbreak in Hubei Province, China. JAMA Pediatr. 2020, 174, 898. [CrossRef]

8. Singh, S.; Roy, A.P.D.; Sinha, C.P.T.M.K.; Parveen, C.P.T.M.S.; Sharma, G.; Joshi, G. Impact of COVID-19 and lockdown on mental health of children and adolescents: A narrative review with recommendations. Psychiatry Res. 2020, 293, 113429. [CrossRef]

9. Giménez-Dasí, M.; Quintanilla, L.; Lucas-Molina, B.; Sarmento-Henrique, R. Six Weeks of Confinement: Psychological Effects on a Sample of Children in Early Childhood and Primary Education. Front. Psychol. 2020, 11, 590463. [CrossRef] 
10. Howard, S.J.; Melhuish, E. An Early Years Toolbox for Assessing Early Executive Function, Language, Self-Regulation, and Social Development: Validity, Reliability, and Preliminary Norms. J. Psychoeduc. Assess. 2017, 35, 255-275. [CrossRef]

11. Calkins, S.D.; Fox, N.A. Self-regulatory processes in early personality development: A multilevel approach to the study of childhood social withdrawal and aggression. Dev. Psychopathol. 2002, 14, 477-498. [CrossRef] [PubMed]

12. Esliger, D.W.; Rowlands, A.V.; Hurst, T.L.; Catt, M.; Murray, P.; Eston, R.G. Validation of the GENEA Accelerometer. Med. Sci. Sports Exerc. 2011, 43, 1085-1093. [CrossRef] [PubMed]

13. Migueles, J.H.; Rowlands, A.V.; Huber, F.; Sabia, S.; Van Hees, V.T. GGIR: A Research Community-Driven Open Source R Package for Generating Physical Activity and Sleep Outcomes From Multi-Day Raw Accelerometer Data. J. Meas. Phys. Behav. 2019, 2, 188-196. [CrossRef]

14. Crotti, M.; Foweather, L.; Rudd, J.R.; Hurter, L.; Schwarz, S.; Boddy, L.M. Development of raw acceleration cut-points for wrist and hip accelerometers to assess sedentary behaviour and physical activity in 5-7-year-old children. J. Sports Sci. 2020, 38, 1036-1045. [CrossRef]

15. WHO. Guidelines on Physical Activity, Sedentary Behaviour and Sleep for Children under 5 Years of Age; WHO: Geneva, Switzerland, 2019.

16. Van Hees, V.; Sabia, S.; Anderson, K.N.; Denton, S.J.; Oliver, J.; Catt, M.; Abell, J.G.; Kivimäki, M.; Trenell, M.I.; Singh-Manoux, A. A Novel, Open Access Method to Assess Sleep Duration Using a Wrist-Worn Accelerometer. PLoS ONE 2015, 10, e0142533. [CrossRef]

17. Goodman, A.; Lamping, D.L.; Ploubidis, G.B. When to Use Broader Internalising and Externalising Subscales Instead of the Hypothesised Five Subscales on the Strengths and Difficulties Questionnaire (SDQ): Data from British Parents, Teachers and Children. J. Abnorm. Child Psychol. 2010, 38, 1179-1191. [CrossRef]

18. Campbell, S.B. Behavior Problems in Preschool Children: A Review of Recent Research. J. Child Psychol. Psychiatry 1995, 36, 113-149. [CrossRef]

19. Jackson, M.I.; Kiernan, K.; McLanahan, S. Maternal Education, Changing Family Circumstances, and Children's Skill Development in the United States and UK. Ann. Am. Acad. Politi Soc. Sci. 2017, 674, 59-84. [CrossRef]

20. Aguilar-Farias, N.; Toledo-Vargas, M.; Miranda-Marquez, S.; Cortinez-O'Ryan, A.; Cristi-Montero, C.; Rodriguez-Rodriguez, F.; Martino-Fuentealba, P.; Okely, A.D.; Del Pozo Cruz, B. Sociodemographic Predictors of Changes in Physical Activity, Screen Time, and Sleep among Toddlers and Preschoolers in Chile during the COVID-19 Pandemic. Int. J. Environ. Res. Public Health 2021, 18, 176. [CrossRef]

21. Monk, T.H.; Petrie, S.R.; Hayes, A.J.; Kupfer, D.J. Regularity of daily life in relation to personality, age, gender, sleep quality and circadian rhythms. J. Sleep Res. 1994, 3, 196-205. [CrossRef]

22. Stern, M.; Wagner, M.H.; Thompson, L.A. Current and COVID-19 Challenges With Childhood and Adolescent Sleep. JAMA Pediatr. 2020, 174, 1124. [CrossRef] [PubMed]

23. Bueno-Notivol, J.; Gracia-García, P.; Olaya, B.; Lasheras, I.; López-Antón, R.; Santabárbara, J. Prevalence of depression during the COVID-19 outbreak: A meta-analysis of community-based studies. Int. J. Clin. Health Psychol. 2021, 21, 100196. [CrossRef] [PubMed]

24. Lubans, D.R.; Richards, J.; Hillman, C.; Faulkner, G.; Beauchamp, M.; Nilsson, M.; Kelly, P.; Smith, J.J.; Raine, L.; Biddle, S. Physical Activity for Cognitive and Mental Health in Youth: A Systematic Review of Mechanisms. Pediatrics 2016, 138, e20161642. [CrossRef]

25. García-Hermoso, A.; Hormazábal-Aguayo, I.; Fernández-Vergara, O.; Olivares, P.R.; Oriol-Granado, X. Physical activity, screen time and subjective well-being among children. Int. J. Clin. Health Psychol. 2020, 20, 126-134. [CrossRef] [PubMed]

26. López-Gil, J.F.; Oriol, X.; Izquierdo, M.; Ramírez-Vélez, R.; Fernández-Vergara, O.; Olloquequi, J.; García-Hermoso, A. Healthy Lifestyle Behaviors and Their Association with Self-Regulation in Chilean Children. Int. J. Environ. Res. Public Health 2020, 17, 5676. [CrossRef]

27. McNeill, J.; Howard, S.J.; Vella, S.A.; Santos, R.; Cliff, D.P. Physical activity and modified organized sport among preschool children: Associations with cognitive and psychosocial health. Ment. Health Phys. Act. 2018, 15, 45-52. [CrossRef]

28. Voss, M.W.; Carr, L.J.; Clark, R.; Weng, T. Revenge of the "sit" II: Does lifestyle impact neuronal and cognitive health through distinct mechanisms associated with sedentary behavior and physical activity? Ment. Health Phys. Act. 2014, 7, 9-24. [CrossRef] 